\title{
How a Smiley Face Can Save the World
}

The Invisible Gorilla: How Our Intuitions Deceive Us

Christopher Chabris and Dan Simons

(Harmony, 320 pp., \$15.00)

Nudge: Improving Decisions about Health, Wealth, and Happiness

Richard H. Thaler and Cass R. Sunstein

(Penguin Books, 320 pp., \$17.00)

Predictably Irrational: The Hidden Forces That Shape Our

Decisions

Dan Ariely

(Harper Perennial, 384 pp., \$15.99)

Simpler: The Future of Government

Cass R. Sunstein

(Simon \& Schuster, 272 pp., \$16.00)

The Upside of Irrationality: The Unexpected Benefits of Defying Logic

Dan Ariely

(Harper Perennial, 368 pp., \$15.99)

The Victory Lab: The Secret Science of Winning Campaigns

Sasha Issenberg

(Broadway Books, 400 pp., \$15.00)

By Tony Mastria

In 2005, the unsuspecting residents of 300 households in San Marcos, California, agreed to take part in what they thought was an experiment in energy use. Little did these wellmeaning rubes realize that the true purpose of the study was to test the effects of social acceptance on basic decision-making, an exercise in IRBsanctioned manipulation that only a jaded social scientist could devise. Needless to say, the results would reveal more about human nature than they would about conservation.

The 300-household sample was divided in two. For four weeks, 
half the participants received regular updates on their personal electricity consumption, including a comparison with the group average. The results were intriguing but unsurprising: residents whose consumption was above the median reduced their use the next time around, while residents whose consumption was below the median increased their use-both economically rational responses known as boomerang effects. Participants on either side of the average reacted just as we might expect: above-average users (sweating under the hot, glaring light of peer pressure and incandescent bulbs) felt compelled to conserve, while below-average users (seeing they were below the socially acceptable level of energy use) decided they could afford to consume more with no consequence.

The other half of participants fared a bit differently. They were given the same information as the first group, plus a small social cue: residents with above-average energy use received a frowny face $*$ with their results, while residents with belowaverage energy use received a smiley face $(-)$. The result? Not only did consumption of above-average users descend toward the average (as it did in the first group), but consumption of below-average users did not change at all (statistically speaking); they maintained their lower levels of electricity use. The boomerang effect had been essentially neutralized. In San Marcos, California, it seems the basic rules of human rationalityundergirded by hundreds of years of systematic, empirical research in economics and the nuances of objective, higher-order reasoning-are no match for a circle, two dots, and an arc arranged to resemble an approving, happy face.

See? :-)

At a time when gridlocked policymakers are grasping for easy solutions to ongoing problems (like reducing carbon emissions with energy-conscious emoticons), the opportunity for audacity has never been riper. The above vignette is just one example of how psychology can drive such policy innovation, from the book Nudge: Improving Decisions about Health, Wealth, and Happiness by Richard Thaler and Cass Sunstein. And Nudge is just one in a series of titles elucidating how the ascending field of behavioral economics (the odd-couple marriage of psychology and economics) can impact our public policy.

Not only does behavioral economics offer new insights for the world of policymaking; it erodes old assumptions and razes old ways. It highlights the limits of traditional (neoclassical) economics, both inside and outside the public sphere, and illuminates new paths for policymakers and private citizens alike.

For instance, behavioral economics explains why losses are more painful than gains are enjoyable, a phenomenon known as prospect theory. Since traditional economics teaches us that rational human beings treat gains and losses equally, this revelation to the contrary is both surprising and significant. For example, in another anecdote on energy use, researchers found that participants were more willing to reduce their electricity consumption if the financial consequences were framed as losses averted ("If you don't upgrade your appliances, you will lose $\$ 100$ in energy costs") rather than money gained ("If you do upgrade your appliances, you will save $\$ 100$ in energy costs"). In this case, the potential losses acted as a more powerful incentive than the potential gains, even though both outcomes meant the same thing. Needless to say, this altered understanding of human rationality has the 
potential to retool our discussions of economic concerns.

Thaler and Sunstein further the case for behavioral economics by noting the power of choice architecture, the notion that people often make decisions based upon how their options are presented. For example, students who eat school lunches are more likely to select healthier meals if fruits, veggies, and other nutritious items are placed at the front of the lunch line. Unfortunately, the converse is also true: students are more likely to eat poorly if they encounter unhealthy items first. As the authors note, this runs counter to traditional economics, which asserts that people make decisions purely on the merits of the options they face - not on how those options are displayed. Given that childhood obesity is one of our most prominent public health concerns today, it's not hard to see the potential for such a small change to yield big results.

Thaler and Sunstein leave no stone unturned in the search for a more sensible understanding of human behavior, spotlighting such economically inexplicable phenomena as anchoring (assigning a numerical value to something based on an unrelated number somewhere elselike basing willingness to pay for a bottle of wine on the last two digits of one's Social Security number); availability bias (judging the likelihood of an event by its frequency or salience in one's personal life-like overestimating the possibility of shark attacks, crime, and lightning strikes); and representativeness (attempting to determine if a phenomenon fits an explainable pattern or is simply the result of chance-like geographical pockets of concentrated illness or "hot hands" in basketball).

Put simply: behavioral economics allows psychology to pick up the pieces where traditional economics falls apart.

Nudge builds on the work of a nascent and growing field, and savvy policymakers would do well to explore this new frontier of economic insight. A good place to start would be the work of Duke University professor Dan Ariely, who has published several books that serve as thorough but intelligible primers for the field, including Predictably Irrational: The Hidden Forces That Shape Our Decisions and The Upside of Irrationality: The Unexpected Benefits of Defying Logic. Ariely synthesizes the research in a way that's easily digestible to readers of all experience levels, combining theoretical ideals with real-world examples.

For instance, Ariely shows that when people are faced with a set of choices, their final decision is affected by every option on the list, even the ones they would never consider selecting in the first place. Ariely describes how he presented one group of students with a real advertisement from The Economist offering three subscription options: a web-only option for $\$ 59$ per year; a print-only option for $\$ 125$; and a print \& web combo option for $\$ 125$. When asked which subscription option they would prefer, students overwhelmingly selected the combo option, while a smaller number selected the web-only option and nobody selected the print-only option. He then presented the same advertisement to a second group of students, minus the print-only option. Because no students in the first treatment selected the print-only option anyway, it seemed reasonable to predict that its absence would have little effect on this second trial. On the contrary: when presented with just a $\$ 59$ webonly option and a $\$ 125$ combo option, most students chose the (cheaper) web-only option. While this variation 
seems illogical from a traditional economic perspective, it makes perfect sense in the psychology-driven world of behavioral economics. In the first trial, students' least-preferred option (\$125 print-only) served as an anchor to evaluate another equal-cost option (\$125 combo), which seemed like a bargain by comparison. Without the presence of that anchor in the second trial, students felt less compelled to snag the seemingly better deal. It's a lesson sensible policymakers would benefit from learning: good governance comes not only from making the right choices, but from presenting the right choices to others as well.

In Simpler: The Future of Government, Cass Sunstein (director of the Office of Information and Regulatory Affairs from 2009 to 2012) builds on his work in Nudge to provide even more examples of behavioral economics in action. For instance, he discusses how small fees on grocery bags demonstrate that loss aversion affects even trivial consumer decisions (a phenomenon DC residents know all too well); he highlights the efforts of savvy British tax collectors who show that appealing to social norms can dramatically improve compliance (by reminding taxpayers, for example, that " 9 out of 10 people in Exeter pay their taxes on time"); and he cites the Federal Trade Commission's EnergyGuide label, which includes an appliance's "estimated yearly operating cost," as an example of "unhiding costs" from otherwise unwary consumers.

We can even look beyond policy decisions to the realm of civic engagement, where behavioral economics can encourage us to be better citizens. Sasha Issenberg's The Victory Lab: The Secret Science of Winning Campaigns describes how election officials, candidates, campaigns, and parties can use social norms to encourage more people to vote. For example, Issenberg describes an experiment conducted during the state of Michigan's 2006 primary election in which 100,000 randomly chosen residents received one of five mailers reminding them to vote. The first letter emphasized "civic duty," a conventional theme in get-out-the-vote efforts, and the second letter informed recipients that their voting behavior was being studied, since simple awareness of being observed might affect their willingness to vote (a phenomenon known as the Hawthorne effect). While the first two mailers appealed to voters' individual behavior, the other two overtly targeted their social norms and peer pressure. The third letter included a chart highlighting the vote history of every voter in the recipient's household (a checklist of the recent elections in which they had and hadn't voted), while the fourth letter included the same chart and compared it to the vote history of the recipient's neighbors. (The fifth letter was an impartial control mailer.) While this fourth letter elicited vociferous complaints from angry recipients, it also elicited their votes, generating a turnout advantage of eight percentage points over the control letter (37.8 percent to 29.7 percent) and similarly impressive margins versus the "civic duty" and Hawthorne treatments (31.5 percent and 32.2 percent, respectively).

While these examples demonstrate behavioral economics' incredible potential as a policy tool, the field is not without controversy. In making their case for greater use of behavioral economics, Thaler, Sunstein, and other proponents often espouse the philosophy of libertarian paternalism, wherein people are given a choice, and decision-makers set the default option to whatever they see as the best choice for most partici- 
pants, without restricting the ability to choose otherwise. For example, an employer with a companywide savings plan might automatically enroll employees in a $401 \mathrm{k}$, but preserve the ability to opt out at any time. This decision may sound innocuous, and perhaps even reasonable, but it highlights an issue that behavioral economics occasionally fails to address: people don't always understand the choices they're making (or not making). Automatic enrollment in a savings plan can assist people with limited financial literacy by helping them build a nest egg and cultivate responsible monetary habits. But it can also hurt people with limited financial literacy if they don't know it's taking place. For someone living paycheck-to-paycheck, in debt or close to it, every dollar counts toward maintaining a decent quality of life. And if an employee is not familiar with, or doesn't fully comprehend, her company's savings policy, she may be jeopardizing her fiscal wellbeing by withholding a significant portion of her salary every week. As valuable as that money may be later on, it can be equally crucial in the moment.

The quandaries surrounding libertarian paternalism can be even more vexing on issues of public health. For example, Thaler and Sunstein note the disparities in organ donation rates between countries with opt-in, opt-out, and active choice models of enrollment. Countries where citizens who apply for a drivers' license are automatically enrolled in organ donation programs (with the ability to opt out) observe much higher rates of organ donation than countries (like the US) where citizens are not automatically enrolled but have the ability to opt in. While this finding can be encouraging to policymakers, it can also raise troubling questions about personal privacy and the nature of consent. Thaler and Sunstein argue that consent is presumed in opt-out systems, but it's unlikely that every participant will be wary of her involvement in the program. In that case, policymakers must ask themselves what level of ignorance, if any, is acceptable when it comes to such an invasive medical procedure. In response, Thaler and Sunstein offer an alternative "mandated choice" model of enrollment, wherein citizens must make a selection (enroll or don't enroll) in order to submit their application; there is no default option. The logic here is that by making an active choice, participants will understand what they're agreeing (or disagreeing) to, while potentially increasing donation rates overall.

Thus, despite its utility as a tool in the policymaker's arsenal, it would be misguided to view behavioral economics as a cure-all for society's ills. Having had a clear influence in just a few areas so far, its potential remains largely unexplored, and it will take years of trial, error, and innovation for policymakers to determine where it can help and where it cannot (or should not). Thaler and Sunstein acknowledge as much by citing some of the primary rebuttals to libertarian paternalism. These include the slippery slope argument (the potential for nudges to evolve into mandates and prohibitions), the possibility that "evil nudgers and bad nudges" could manipulate people maliciously, the principle that government policies ought to strive for neutrality (which libertarian paternalism intentionally upends), and the reality that free people have a "right to be wrong" (even in cases where their decisions may be disadvantageous or even harmful to themselves).

Sunstein furthers this discussion in Simpler. In addition to the concerns outlined above, he says, lib- 
ertarian paternalism strikes many as a hindrance to the free market itself, to the extent that it mandates or preempts certain behavior by businesses and their customers (like requiring products to carry a specific label or preventing consumers from buying items that fail to meet a particular regulatory standard). While Thaler and Sunstein attempt to explain away these concerns - characterizing many of them as either overblown or oversimplified - it's clear that they will continue to percolate so long as behavioral economics remains a prominent player in policy debates.

Finally, in considering the role that behavioral economics can occupy in our policy discussions, it's worth asking how well we truly understand human psychology at all. That is, if behavioral economics exposes the limitations of the "economic" side of the equation, what does it say about the "behavioral" side? In truth, perhaps not much. In The Invisible Gorilla: How Our Intuitions Deceive Us, Christopher Chabris and Daniel Simons reveal that many of our natural responses to everyday situations stem from "illusions" in how we perceive the world around us. For example, the "illusion of attention" (that we are adept at discerning the details of our surroundings) explains why one can watch a video about basketball while failing to notice a gorilla walking through the middle of the screen. Meanwhile, the "illusion of memory" (that our minds store information with total clarity and accuracy) explains how eyewitness testimony fueled by false memories can punish innocent people for crimes they did not commit. In total, Chabris and Simons unearth six illusions of human perception (including knowledge, confidence, cause, and potential), all of which have clear implications for public policy. So as we recognize how far we are from being purely rational decision-makers and begin to embrace a more psychology-centered style of policymaking, it's crucial that we concede not only the faults in our theories but also the flaws within ourselves.

Limitations notwithstanding, it's clear that behavioral economics has a role to play in our policy debates and will only grow in importance as our societal concerns become larger and more complex. Thus, it's up to policymakers to broaden their analyses beyond conventional economic considerations and begin to integrate these basic principles of human psychology into their decisions. And as our country's rising class of leaders and lawmakers, it's contingent upon us to realize the benefits of this slow, quiet revolution in political understanding. It may be a bit of an overstatement to suggest that behavioral economics can save the world, but surely it's worth at least one of these. :)

Tony Mastria is in his second and final year at the Trachtenberg School and is excited to earn his Master of Public Administration in May 2015. He currently works as a Digital Media Associate for the Justice Policy Institute, where he spends the majority of his day on Facebook and Twitter. Before coming to DC, Tony graduated from the University of California, Los Angeles, with a Bachelor of Arts in Political Science and minors in Public Affairs, Civic Engagement, and Environmental Systems and Society. He looks forward to the day he can return to California and forever banish the concept of "winter" from his life. In 
his free time, he likes to eat ice cream and really enjoys a nice pair of slacks.

Tony would like to present a smiley face $:$ to all the people who played a role in helping this article come to fruition. First, he offers his utmost thanks to his editors Christine Mellen and Mathew Vicknair, without whose guidance and gentle nudges this article likely would have been completed the night beforeand not nearly as refined and professional as it came to be. In addition, he would like to extend his gratitude to the Sunnyvale Public Library for giving him the means and inspiration to begin exploring this subject, without asking anything in return but his library card and frequent late fees. If this article is ever deemed worthy enough to grace its shelves, Tony will no doubt express his appreciation through a generous contribution. Finally, Tony would like to thank his family, whose love, support, and unsolicited care packages gave him the tools he would need to see this project through to the end. (In return, you can now brag to friends and relatives about him being a "published author.") 